\title{
A Case Study on the Microstructure of Fibrous Peat (West Lake, China)
}

\author{
Stephen Wilkinson ${ }^{1}$, Chaofa Zhao ${ }^{2}$, Zhongxuan $\mathrm{Yang}^{3}$ and Kun $\mathrm{Pan}^{3}$ \\ ${ }^{1}$ University of Wolverhampton, Wolverhampton WV1 1LY UK \\ Formerly Department of Civil Engineering, Xi'an Jiaotong-Liverpool University, Suzhou, \\ Jiangsu, China \\ ${ }^{2}$ Formerly Department of Civil Engineering, Zhejiang University, China \\ ${ }^{3}$ Department of Civil Engineering, Zhejiang University, China
}

\begin{abstract}
The classification of peat soils generates a very large number of different types, from a descriptive perspective this is useful, however such a system generates too many options for engineering purposes. The behaviour of organic soils varies based on the quantity and type of organic material present within the soil. The effects of fibre content are particularly important. The West Lake in Hangzhou has been dredged many times during its history to allow it to maintain its beauty. During the most recent dredging the sludge from the lake was transported via a $4 \mathrm{~km}$ pipeline and deposited inside the Jiangyangfan Reservoir. The organic soil situated in Jiangyangfan Ecopark is a particularly interesting peaty material. The organic sludge was mixed and homogenised during the transportation process, and then would have settled out within the reservoir. This resulted in a more than $20 \mathrm{~m}$ thick peat layer deposited with an uneven surface. The Ecopark buildings were then constructed on top of this in 2008. A combined electron microscope and mechanical study of the microstructure and behaviour of the peat has been used to identify the engineering impact of the presence of relatively small numbers of fibres within the soil matrix. The fibres within the peat modify its behaviour such that it can no longer be understood within the typical critical state framework for soils. The peat starts to plastically deform from very small levels of applied stress, in addition it does not display a tension cut-off failure, and ultimately fails in shear.
\end{abstract}

Keywords: Peat, Classification, Microstructural Imaging, Organic Fibers, Microstructure Assessment

\section{Introduction}

The West Lake (Xihu) in Hangzhou is recognised as a UNSECO World Heritage site due to its inspiration of Chinese painters and poets throughout history. The lake, originally a lagoon, on the banks of the Qiantang River, is fed by small rivers in the surrounding hills. Given its locality it is gradually being infilled by transported sediment and organic debris from the surrounding hillslopes. These natural processes have been resisted by human intervention in order to preserve the natural beauty of the site. The 
lake has been dug out several times in history. In fact, the first time the lake was referred to as "West Lake", was in 1090 when the then governor Su Shi, also a wellknown poet, made a request for soldiers to be sent to dig out the lake (Shi, 1090). This long term history of dredging of the lake has produced deposits of peaty soil (which is a form of made ground) across the hills surrounding Hangzhou.

During one of the most recent engineering works to prevent the silting up of the West Lake, in 1999, a dredging method was employed. A $4 \mathrm{~km}$ long pipeline was built to transport dredged soil and organic debris from the lake across the hills to a small reservoir on the north bank of the Qiantang River. Due to the large quantities of peat the reservoir was almost completely filled with this debris (approximately 1,000,000 $\mathrm{m}^{2}$ of sludge). After completion of the dredging work, the newly filled reservoir, known as the Jiangyangfan site, was allowed to settle under its own weight for five years (to 2008). Following which construction of an eco-park commenced on the site.

Due to the sites anthropogenic depositional history the material within the Jiangyangfan eco-park is pretty unique. There is an $18 \mathrm{~m}$ thick sequence of rapidly deposited mixed organic and siliciclastic material. The soil constituents would have been very well mixed in the turbulent conditions present inside the pipeline. Any structures and layering of the peat sequence produced at Jiangyangfan would be generated by the movement of the dredging apparatus across the lake. It is thus anticipated that the amount of variation that this would produce in any layer would be minimal. The produced peat can be described as fibrous. However due to the transportation process the fibres tend to be short and well-distributed. This distribution of fibres allows this particular peat to exhibit intermediate behaviours (outlined later).

During the construction of the eco-park, as could be expected, issues with excessive settlement were encountered. Settlements of up to $0.7 \mathrm{~m}$ were measured during monitoring of the structures. This triggered an investigation into the behaviour of the peat, which was to contribute to mitigation works.

\section{Peat Assessment}

The classification methods available for peat are cumbersome, reflecting the broad variety of different materials identified as peat. Typically the classification of peat is carried out using one of two major classification systems, the Von Post system focusing on rural land management requirements, and the Radford system focusing on the peats internal structure. The Radford system splits peat into two major categories, amorphous and fibrous, with the fibrous category being subdivided into majority coarse and majority fine fibres. The Von Posts classification system is more extensive covering humification, water content, organic content, fine and coarse fibre content and wood content. Given this, the Von Post system provides a more rounded description of peats, however it lacks some important elements which could assist in understanding the engineering behaviour of peaty soils. Hobbs (1986) identified this lack and extended the Von Post system to include organic content, tensile strength in the vertical and horizontal directions, odour, plastic limit and acidity. The classification system produced in this way generates 245,760,000 unique classifications for peat 
materials (Table 1). This provides too many options to be used practically to divide peats up into different behavioural systems for engineering purposes. It is however important to note that some of these options are not practically possible (i.e. a peat with high humification cannot also have fibres). Having said this, the description produced by this method is of great use in assessing the potential behaviours of the peat and providing a comparative identification of the layers within a peaty formation. An engineering focused classification system which identifies the range of behaviours of peat, while limiting the ultimate number of types would be more useful. However more resent analysis suggests that the variations in peat from region to region mean that it is unnecessary and indeed impossible to create a unified classification system (Landva, et al. 1983). Given the variation in vegetation types that might act as a source for peat, locally driven systems may be the answer. However these must take account of, and allow for, broader correlations to be made. At present, the authors recommend the modified von Post system as an aid to description and that classification be carried out using a reduced locally focused system.

Table 1. The number of options for each sub classification in the von Post classification system for peat, as extended by Hobbs (1986)

\begin{tabular}{|c|c|c|c|c|c|c|c|c|c|c|c|c|c|c|}
\hline 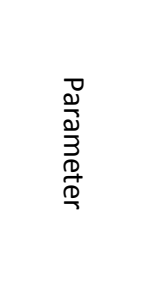 & 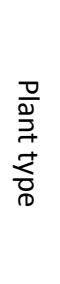 & 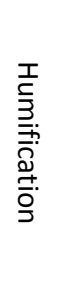 & 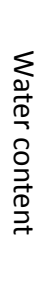 & 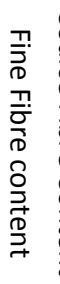 & 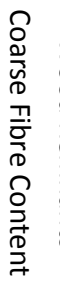 & 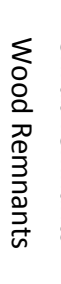 & 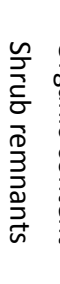 & 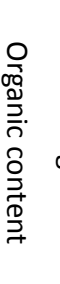 & 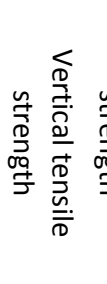 & 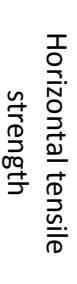 & $\begin{array}{l}\text { 응 } \\
\stackrel{0}{\circ} \\
\cong\end{array}$ & 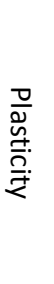 & $\begin{array}{l}\frac{\triangleright}{2} \\
\frac{0}{\risingdotseq}\end{array}$ & Total \\
\hline $\begin{array}{c}\text { Number of } \\
\text { Options }\end{array}$ & 10 & 10 & 5 & 4 & 4 & 4 & 4 & 5 & 4 & 4 & 4 & 2 & 3 & $245,760,000$ \\
\hline
\end{tabular}

\section{The West Lake Peat}

The West Lake Peat has undergone a homogenisation process during transport within the pipeline to the Jiangyangfan site. The organic content has been mixed with large quantities of silt and the turbulent flow of this mixture within the pipeline would have resulted in a degradation of the quality and interconnectedness of the existing fibres. Using the modified von Post system, the peat is defined as a bryales moss peat, it has moderate humification, with intermediate water content, a high but non-dominant quantity of fine fibres with low coarse fibre content and no wood. Its organic content is low, it has moderate tensile strength in both the vertical and horizontal directions, it has a slight odour, a measurable plastic limit and is acidic. 

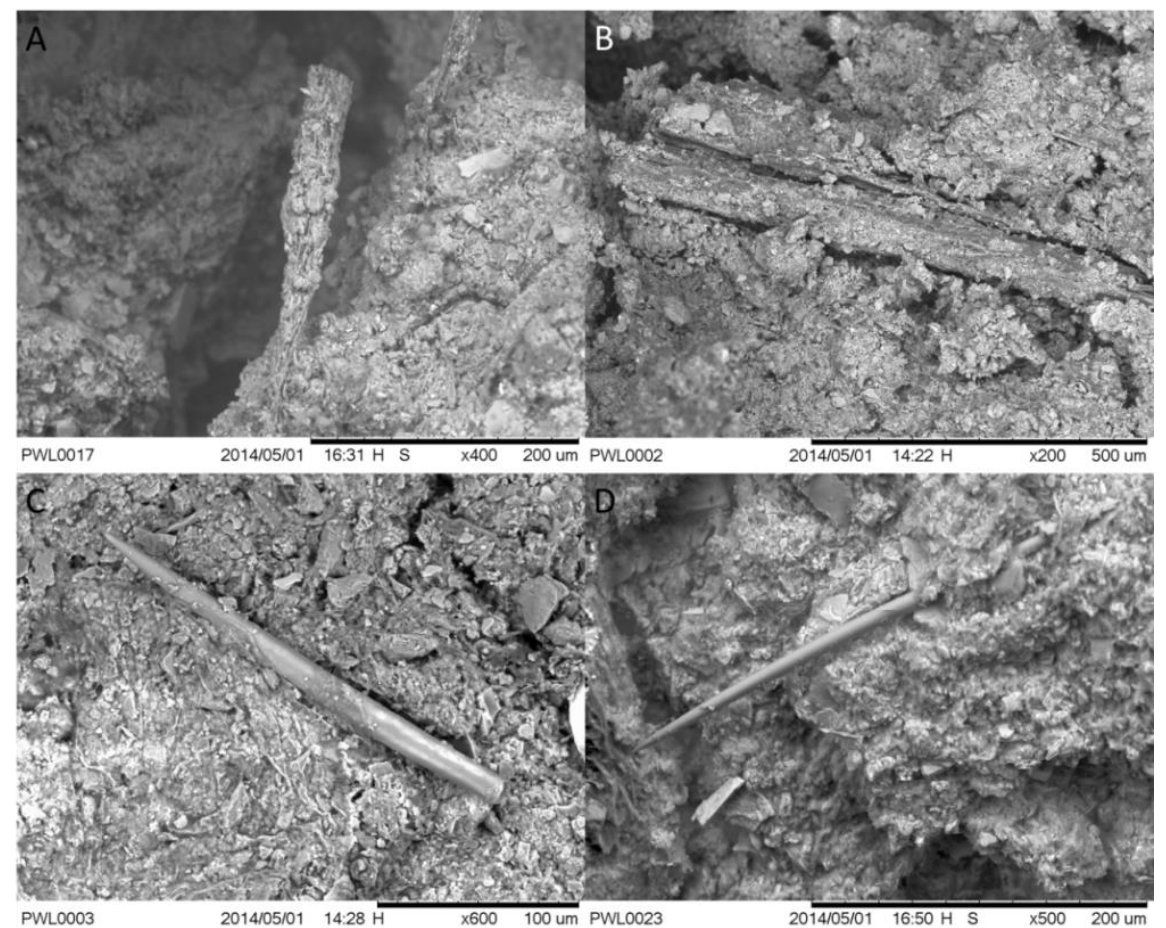

Fig. 1. Examples of fibres (fine) found within the West Lake Peat. A) Rough fibres that have been pulled during the formation of the broken surface for imaging. B) Rough fibres embedded in the matrix of the peat showing distinct separation between the fibre and the surrounding soil. C \& D) examples of smother fibres within the peat matrix.

In terms of its engineering behaviour, its fibre content being high but not dominant is important as is its low organic content (Yang et al. 2016). The peats engineering behaviour is discussed further below.

As part of the investigation into the behaviour of the West Lake Peat a scanning electron microscope (SEM) assessment was carried out using the Hitachi TM300 tabletop microscope imaging facility at Xi'an Jiaotong Liverpool University. One key feature identified in the SEM analysis was the relative lack of fibres and fibrous matter in comparison to most peats (Fig. 1). Much of the groundmass of the peat is siliciclastic in origin. However, the reasonable tensile strength of the peat is an indicator the presence of fibrous material, and although sparse several types of fibre were identified within the peat. Multi-strand fibres were identified (Fig. 1 A \& B). In some instances, these fibres displayed evidence of resisting the tensile force used to generate the broken surface for imaging (Fig. 1A). In addition, several smoother fibres (root like) were identified. These would provide less frictional resistance and thus have a lower contribution to the tensile stresses (Fig. $1 \mathrm{C} \& \mathrm{D}$ ). Different types of fibres and fibre structures can also be observed at the smaller scale (Fig. 2). These vary from fairly rigid and well-structured microfibers with rough surfaces (Fig. 2 A), 
to more ductile less structured rough fibres (Fig. 2 B), and to smoother root structures (Fig. 2 C).

In addition, the variability of the West Lake Peat is also displayed in its microscale particles and structures. Pyritic framboids typically form post deposition (during burial) and are indicative of a reducing environment (Fig. 2 D). Diatoms may have been present in the sludge at the base of the lake, or may have been sucked directly from the lake water (Fig. 2 E).
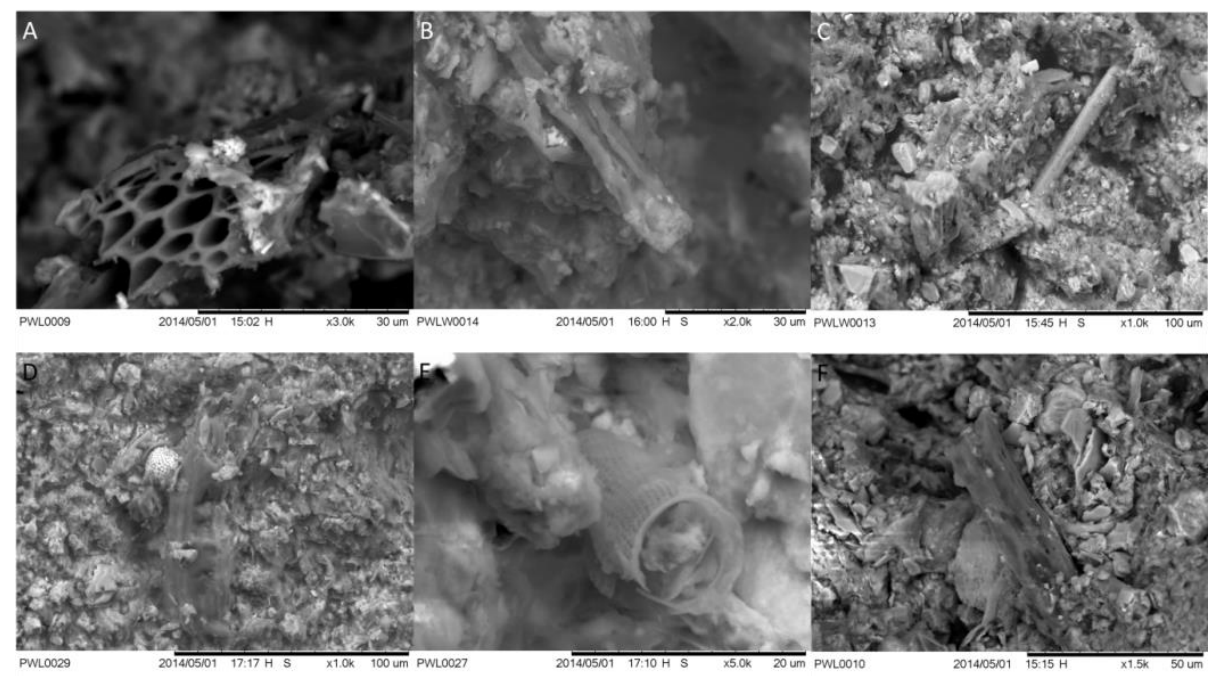

Fig. 2. Examples of small scale structures within the West Lake Peat A) sections of plant fibres showing xylem and phloem B) crumpled and degraded plant fibres C) granular matrix of the peat and small fibrous structures D) pyritic framboid and leaf like structures E) diatom from the West Lake F) Crumpled leaf like structures.
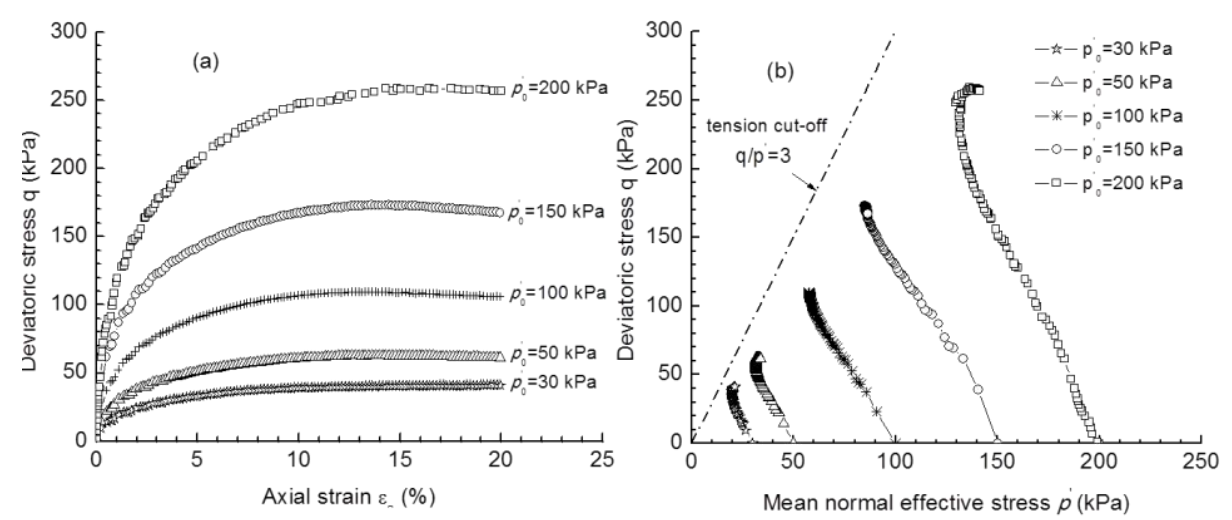

Fig. 3. Triaxial Compression results for the West Lake Peat (modified from Yang et al 2016) 
Leaf structures were observed in multiple locations, forming a large proportion of the organic matter in the peat (Fig. 2 F).

As a part of the geotechnical assessment of the soil a range of classification and mechanical test of the West Lake Peat were carried out (Yang et al 2016). The key observed behaviours of the West Lake Peat are: the soils angle of friction was high, however it did not reach the tension cut-off criteria, and so failed in shear (Fig. 3). The majority of fibrous peats fail in tension, so this is unusual behaviour. It is clear that the presence of a quantity of fibres has enhanced the peats strength (angle of friction), but that the fibres do not dominate the peats behaviour. These test results match well with the SEM observations, that the fibres are present, but are well separated.

\section{Conclusions}

Classification systems for peat produce a very large number of different possible outcomes. This is a result of the inclusion of the wide range of parameters that would be importation for geotechnical engineering, and it is clear that having such information in the description of the soil is very important. But attempts to use such systems for classification in order to make correlations between sites (or even samples) to compare engineering behaviour will be problematic. The utilisation of local classification systems to allow local correlations with less chance for confusion is recommended.

The West Lake Peat due to its unique geological history, had an unusual structure, with fibres present and clearly influencing the engineering behaviour of the soil. But the peat still failed in shear rather than in tension. This interesting result highlights the variability of peat systems and indicates the importance of evolving peat models to include more elements of its behaviour.

\section{Acknowledgement}

The research was funded by the Natural Science Foundation of China (Grant Nos. 51578499).

\section{References}

Hobbs, N.B.: Mire morphology and the properties and behaviour of some British and foreign peats. Quarterly Journal of Engineering Geology 19, 7-80 (1986).

Landva, A. O., Korpijaakko, E. O., Pheeney, P. E.: "Geotechnical classification of peats and organic soils. Testing of peat and organic soils, STP 820, ASTM, West Conshohocken, Pa. 37-51. (1983).

Radforth, N.W.: Classification of muskeg. In: MacFarlane, I. C. (ed.) Muskeg engineering handbook. Canadian Building Series. University of Toronto Press. (1969).

Shi, S.: The request of dredging West Lake in Hangzhou. http://blog.sina.com.cn/s/blog_500bc46501012fe3.html (in Chinese), (1090). 
von Post, L.: Sveriges Geologiska Undersoknings torvinventering och nogra av dess hittils vunna resultat (SGU peat inventory and some preliminary results). Svenska Mosskulturforeningens Tidskrift, Jonkoping, Sweden 36, 1-37 (1922).

Yang Z.X., Zhao C.F., Xu C.J., Wilkinson S.P., Cai Y.Q., Pan K.: Modelling the engineering behaviour of fibrous peat formed due to rapid anthropogenic terrestrialization in Hangzhou, China. Engineering Geology 215, 25-35 (2016). 